\title{
Desafios dos estudantes ou egressos dos Cursos de Licenciatura do IFMT Campus Confresa na elaboração do Trabalho de Conclusão de Curso
}

\author{
Challenges of students or graduates of the Licentiate Courses of the IFMT Campus Confresa in the \\ preparation of the Course Conclusion Work \\ Desafíos de los alumnos o egresados de las Licenciaturas de la IFMT Campus Confresa en la \\ elaboración del Trabajo de Conclusión del Curso
}

Recebido: 17/08/2021 | Revisado: 22/08/2021 | Aceito: 23/08/2021 | Publicado: 24/08/2021

Andrielle Naiara Silva Costa
ORCID: https://orcid.org/0000-0003-0186-5244
E-mail: andrielle.nsc@gmail.com
Marcelo Franco Leão
Instituto Federal de Educação, Ciência e Tecnologia do Mato Grosso, Brasil
ORCID: https://orcid.org/0000-0002-9184-916X
E-mail: Marcelo.leao@crs.ifmt.edu.br
Ana Claudia Tasinaffo Alves
Instituto Federal de Educação, Ciência e Tecnologia do Mato Grosso, Brasil
ORCID: https://orcid.org/0000-0003-0670-1978
Instituto Federal de Educação, Ciência e Tecnologia do Mato Grosso, Brasil
E-mail: ana.alves@ifmt.edu.br

\begin{abstract}
Resumo
O Trabalho de Conclusão de Curso (TCC), requisito obrigatório na maioria dos cursos de Graduação, envolve um estudo de cunho científico, com leituras, coleta e análises de dados, além de possuir normas e formatos específicos, que muitas vezes provocam dificuldades aos estudantes. A pesquisa teve como objetivo descrever as percepções dos estudantes concluintes ou egressos dos Cursos de Licenciatura do IFMT Campus Confresa sobre os desafios enfrentados durante a escrita de seus TCCs. Essa pesquisa, do tipo descritivo e de abordagem qualitativa, ocorreu em março de 2021 e envolveu 30 participantes entre estudantes concluintes e egressos de Cursos de Licenciatura do IFMT Campus Confresa. Como instrumento de coleta de dados foi utilizado um formulário eletrônico constituído por 26 perguntas, sendo 05 abertas e 21 fechadas. Foram apontados diversos desafios pelos sujeitos da pesquisa, entre eles os mais citados foram à dificuldade na escrita científica, compreensão e uso das normas técnicas, assim como a escolha e definição de um tema. Aos estudantes que estavam concluindo o TCC foi questionado se nesse período pandêmico tiveram impactos na elaboração do TCC, a maioria respondeu que está sendo difícil, principalmente quanto a manter o distanciamento do orientador, colegas, instituição, a dificuldade de coleta de dados e a defesa online. Para concluir, é possível afirmar que o TCC é um desafio para os estudantes, principalmente na escrita e familiarização com as normas de formatação.
\end{abstract}

Palavras-chave: Escrita científica; Monografia; Pesquisa científica.

\begin{abstract}
The Course Conclusion Work (CCW), a mandatory requirement in most undergraduate courses, involves a scientific study, with readings, data collection and analysis, in addition to having specific standards and formats, which often cause difficulties for students. The research aimed to describe the perceptions of students or graduates of Licentiate Courses at the IFMT Campus Confresa about the challenges faced while writing their CCWs. This research, descriptive and qualitative in approach, took place in March 2021 and involved 30 participants, including senior students and graduates of Licentiate Courses at the IFMT Campus Confresa. As a data collection instrument, an electronic form consisting of 26 questions was used, with 05 open and 21 closed. Several challenges were pointed out by the research subjects, among them the most cited were the difficulty in scientific writing, understanding and use of technical standards, as well as the choice and definition of a theme. Students who were completing the CCW were asked if this pandemic period had impacts on the preparation of the $\mathrm{CCW}$, most responded that it has been difficult, especially in terms of keeping the distance from the advisor, colleagues, institution, the difficulty of data collection and defense online. To conclude, it is possible to say that the CCW is a challenge for students, especially in writing and familiarization with formatting standards.
\end{abstract}

Keywords: Scientific writing; Monography; Scientific research. 


\begin{abstract}
Resumen
El Trabajo de Conclusión del Curso (TCC), requisito obligatorio en la mayoría de los cursos de pregrado, implica un estudio científico, con lecturas, recolección y análisis de datos, además de contar con estándares y formatos específicos, que muchas veces ocasionan dificultades a los estudiantes. La investigación tuvo como objetivo describir las percepciones de los estudiantes o egresados de los Cursos de Licenciatura en el IFMT Campus Confresa sobre los desafíos que enfrentan al redactar sus TCC. Esta investigación, de enfoque descriptivo y cualitativo, se llevó a cabo en marzo de 2021 e involucró a 30 participantes, entre estudiantes de último año y graduados de Licenciaturas en el IFMT Campus Confresa. Como instrumento de recolección de datos se utilizó un formulario electrónico compuesto por 26 preguntas, con 05 abiertas y 21 cerradas. Los sujetos de investigación señalaron varios desafíos, entre los cuales los más citados fueron la dificultad en la redacción científica, comprensión y uso de estándares técnicos, así como la elección y definición de un tema. A los estudiantes que estaban completando el TCC se les preguntó si este período pandémico tuvo impactos en la preparación del TCC, la mayoría respondió que ha sido difícil, especialmente en términos de mantener la distancia del asesor, colegas, institución, la dificultad de recolección de datos y defensa en línea. Para concluir, es posible decir que el TCC es un desafío para los estudiantes, especialmente en la escritura y familiarización con los estándares de formato.
\end{abstract}

Palabras clave: Escritura científica; Monografía; Investigación científica.

\title{
1. Introdução
}

O Trabalho de Conclusão de Curso (TCC) é requisito para colação de grau em grande parte dos cursos de graduação das Instituições de Ensino Superior (IES). A escrita e elaboração deste documento devem ser de natureza científica, ou seja, integra as regras que são conforme as normatizações da IES, e são sujeitas as normas da Associação Brasileira de Normas Técnicas (ABNT). Assim, o TCC prepara o estudante na introdução do contexto científico em sua vida acadêmica e profissional.

Os TCCs advindos das IES são responsáveis por grande parte da produção científica do nosso país (Carmo; Machado \& Cogan, 2015). De forma geral, o TCC é um trabalho, de rigor científico, que gera ansiedade entre os estudantes, em razão de ser sistematicamente avaliado. Neste processo educativo são analisadas a escrita, coerência, coesão, apresentação e profundidade de conhecimentos acerca do objeto de estudo, além de ser um requisito de qualificação para aprovação final dos cursos de graduação.

Nesse contexto, antes de realizar o TCC o estudante terá de escolher um tema, definir método e o campo da pesquisa, e tudo isso alicerçada sobre fundamentações científicas (Carboni \& Nogueira, 2004). Diante desse cenário, um fator evidenciado são as dificuldades dos estudantes na elaboração do TCC. Essas dificuldades podem estar relacionadas a diversas problemáticas, podendo ser caráter individual, institucional, entre outras características. As principais dificuldades do TCC são a escrita de cunho científico e a normatização inerente à escrita científica (Brunetta, et al., 2011).

Sobre as problemáticas na elaboração do TCC, Carboni e Nogueira (2004) descrevem que os estudantes apresentam dificuldades em compreender o método a ser empregue, a forma de referenciar as citações, o raciocínio coerente necessário à escrita, a forma de apresentar os resultados, além da coerência entre tema, problema de pesquisa, objetivos, métodos e conclusão.

Diante do exposto, o presente estudo teve como objetivo descrever as percepções dos estudantes concluintes ou egressos dos cursos de Licenciatura do Instituto Federal de Educação, Ciências e Tecnologia do Mato Grosso (IFMT) Campus Confresa sobre os desafios durante a escrita de seus TCCs. Desse modo, espera-se conhecer os principais desafios, ou seja, fatores latentes negativos e positivos que afetam o desempenho dos estudantes neste processo de elaboração, bem como propor soluções que possam sanar ou minimizá-los.

Para tanto, foi estabelecido os seguintes objetivos específicos: Identificar os desafios na elaboração do TCC indicados pelos estudantes de Licenciaturas do IFMT Campus Confresa; Comparar as distintas respostas dos estudantes e a suas percepções acerca do tema; e promover uma reflexão sobre como minimizar e/ou extinguir esses problemas.

Tal tema se faz pertinente por versar de um assunto com grande importância universitária, visto que, na maioria dos 
Cursos de Graduação, é mediante a aprovação do TCC que o estudante obtém o seu diploma. Paralelamente a esse fato, se observa que há uma lacuna de pesquisas no que concerne à compreensão dos estudantes de graduação quanto à contribuição do TCC em sua jornada acadêmica, bem como os desafios enfrentados por eles.

Em vista disso, parte-se da hipótese de que os estudantes se sentem perdidos quando eles necessitam elaborar o TCC. Dessa forma, possuem muitas dúvidas a respeito de como redigi-lo, isso devido ao pouco contato que eles vivenciam durante a Graduação, com tais situações de redação científica. Nesse sentido, para viabilizar a verificação da hipótese, realizou-se a pesquisa de natureza básica, de abordagem qualitativa e objetivo descritivo.

\section{Reflexões Teóricas sobre o Trabalho de Conclusão de Curso}

O TCC é um dos diversos formatos de produção acadêmica, em que as IES avaliam os seus estudantes ao final do curso de graduação. Carmo, Machado e Cogan (2015) conceituam o TCC como uma atividade científica, que é feita na graduação ou pós-graduação, podendo ser um relatório analítico de pesquisa, artigo, monografia entre outros. O TCC possui um padrão a ser seguido, como característica de um trabalho avaliativo, é por meio dele que o estudante de graduação poderá explorar assuntos de seu interesse de forma aprofundada, mediante a pesquisa. Em síntese, o TCC é um trabalho científico.

A pesquisa científica é descrita por Zambello et al. (2018) como algo que parte da nossa realidade, no qual não conseguimos ver ou compreender, podendo ser fenômenos ou fatos, logo, precisa ser desvendado. Silva e Menezes (2005 p. 19) descrevem que "pesquisar significa, de forma bem simples, é procurar respostas para indagações propostas".

De forma geral, a pesquisa científica precisa reunir informações de forma meticulosa para encontrar uma solução de um determinado problema. A pesquisa científica não pode ser conduzida de qualquer jeito, ela precisa ter um método que permite construir conhecimentos concebíveis e acessíveis. Lakatos e Marconi (2003 p. 83) definem o método como sendo um "conjunto das atividades sistemáticas e racionais que, com maior segurança e economia, permite alcançar o objetivo [...], traçando o caminho a ser seguido, detectando erros e auxiliando as decisões do cientista".

Para que o TCC tenha um rigor científico, é necessária uma regulamentação em relação a sua estrutura e formatação. A Associação Brasileira de Normas Técnicas (ABNT) é o órgão privado e sem fins lucrativos, com essa finalidade de padronizar as produções técnicas no Brasil, ou seja, sua normatização é seguida por todos os trabalhos de cunho científico, a exemplo do TCC (ABNT, 2011).

Por conseguinte, a norma ABNT NBR 14.724 (2011) define o TCC como um documento que tem como objetivo expressar o conhecimento de determinado assunto previamente escolhido; e deverá ser apresentado e acompanhado por um orientador, tendo a obrigatoriedade na emissão do módulo, disciplina, curso entre outros.

Segundo os Pareceres No 776/1997 e No 583/2001, do Conselho Nacional de Educação (CNE), fica estipulado que o TCC não é obrigatório nos cursos de graduação. Implicando assim que cada curso de graduação tenha suas Diretrizes Curriculares Nacionais (DCN), em que nesses documentos detêm informações sobre a especificidade da obrigatoriedade do TCC em determinado curso de graduação, podendo ser não obrigatório, obrigatório ou omisso.

A DCN para a formação de professores (Brasil, 2019) não apresenta o TCC como uma obrigatoriedade, o que o torna opcional pela IES a escolha da regra que melhor lhe parecer, mas estes deverão estar no estatuto de regimento geral da IES. Os formatos de TCC são instituídos também pelas IES em seus projetos pedagógicos de cursos, no qual pode ter vários formatos, como monografia, artigo científico, estudo de caso entre outros, tendo a possibilidade de ser elaborado individualmente ou em grupo.

Ademais, para as IES, em que o TCC é opcional ou obrigatório, deve-se ter um regulamento feito pela própria IES constando todas as suas regras e especificações para a sua elaboração e deve conter no Projeto Pedagógico de Curso (PPC). Clemente e Santos (2015) afirma que o TCC é importante para os estudantes ao nível de graduação, visto que é um trabalho 
que promove a pesquisa científica, desenvolvendo assim contribuições científicas para todos envolvidos. Desse modo, o TCC vai além de estruturas metódicas e normatizações, ele estimula o amadurecimento profissional e intelectual que são essenciais para a formação acadêmica.

Na pesquisa realizada por Antunes et al. (2011) foi avaliado a percepção dos estudantes no processo de escrita do TCC, sendo eles do curso de Especialização em Negociação Coletiva, na modalidade a distância. Utilizaram de estudo de caso, com 288 dos estudantes matriculados no curso. Seus resultados destacaram como principal desafio na confecção do TCC, a falta de tempo, dificuldade de familiarização com as normas técnicas, relacionamento com os orientadores e dificuldades na escrita cientifica.

Guedes e Guedes (2012) investigaram a percepção dos estudantes de graduação em Medicina sobre a escrita do TCC. $\mathrm{Na}$ oportunidade, foi utilizado um questionário, a 42 estudantes, e entrevista com 8 dos estudantes. Eles concluíram que os estudantes consideraram a elaboração do TCC uma etapa importante para sua vida acadêmica e profissional, que destacaram terem se sentidos jubilosos pela realização de seus TCC, mesmo este sendo trabalhoso.

Diferentes resultados foram evidenciados por Guimarães e Silva Sobrinho (2020), que procuraram compreender os elementos facilitadores e dificultadores a construção de um TCC. A pesquisa foi por meio de um questionário aplicado a 28 estudantes de graduação da Universidade Federal do Piauí, Campus Floriano. Constatou que os elementos facilitadores foram o bom relacionamento com o orientador e como dificultadores a mudança de orientador, acervo da biblioteca, tempo e o custo indireto e direto necessário à elaboração do TCC.

Assim, é possível compreender que o TCC vai além de estruturas metódicas e normatizações, ele favorece o amadurecimento profissional, por meio das observações de situações e através da pesquisa, estimula o aperfeiçoamento intelectual, que são essenciais para a vida acadêmica e profissional.

\section{O TCC no Contexto dos Cursos de Licenciatura do IFMT Campus Confresa}

O IFMT Campus Confresa iniciou suas atividades no ano de 2010, ofertando os cursos de Ensino Médio Técnico em Alimentos e Agropecuária, integrados ao Ensino Médio; e cursos de Ensino Superior, como Bacharelado em Agronomia, período integral e os de período noturno, que são: Licenciatura em Ciências Agrárias e Licenciatura em Ciências da Natureza com Habilitação em Química. Em 2015 o Campus passou a ofertar os cursos de Licenciatura em Biologia e em Física, encerrando os cursos de Licenciatura em Ciências Agrícolas.

Cabe ressaltar que a missão do IFMT é "proporcionar a formação científica, tecnológica e humanística nos vários níveis e modalidades de ensino, pesquisa e extensão, de forma plural, inclusiva e democrática, pautada no desenvolvimento socioeconômico local [...]”. (IFMT, 2014).

Assim, os cursos de Licenciaturas possuem como objetivo geral a formação de professores para a Educação Básica, bem como participar e promover melhorias na educação utilizando de ferramentas e métodos que aperfeiçoe a qualidade educacional da região em que a IES está inserida. Neste sentido, não se pode dissociar a pesquisa do processo de ensino aprendizagem dos futuros professores (IFMT, 2019).

Conforme consta nos Projetos Pedagógicos dos cursos (IFMT, 2019), as Licenciaturas do IFMT Campus Confresa possuem disciplinas de núcleo comum até o $4^{\circ}$ semestre. Embasadas nas DNC das Licenciaturas, as disciplinas dos cursos foram fundamentadas da seguinte forma: Conteúdos de formação básica: conteúdo humanístico, filosófico, com destaque nos fundamentos de investigação cientifica, ampliação cultural e na construção de pensamento crítico; Conteúdo de formação específica: relacionadas a cada área específica de cada um dos cursos de Licenciaturas; Conteúdos de formação pedagógica: relativo a conteúdos de práticas de ensino.

Além desses componentes curriculares, o IFMT possui formação específico-pedagógico, em que o principal enfoque é 
a metodologia de ensino de ciências da natureza e a instrumentação para o ensino de ciências. E também os componentes curriculares optativos, que são disciplinas ofertadas opcionalmente, mesmo que obrigatória a outras Licenciaturas.

Atualmente o estudante precisa cursar um total de carga horária mínima de 3212 horas, sendo destas: 200 horas em Atividades Acadêmicas, Científicas e Culturais (AACC), 140 horas em participação no Seminário Integrador de Conteúdos (SIC), 160 horas de TCC e 400 horas de Estágio Supervisionado (IFMT, 2019). As AACC são atividades que possibilita a participação e vivência em diferentes áreas de saberes, que exercita a autonomia do estudante em compor seu currículo acadêmico em que estudante julgue ser útil para sua formação profissional.

O SIC tem como objetivo a multidisciplinaridade e interdisciplinaridade dos cursos de Licenciaturas. Sendo confeccionados trabalhos de caráter de ensino, pesquisa e extensão, de temática livre, individual ou em grupo de até três estudantes. Os estudantes, com auxílio de um orientador, deverão apresentar o trabalho ao final do semestre, de modo que no final do curso o estudante está mais familiarizado para a defesa do TCC.

As matérias relacionadas ao TCC são: Metodologia do Trabalho Científico (MTC) e a de TCC. A disciplina de MTC é obrigatória, sendo ofertada no $1^{\circ}$ semestre. Sua ementa visa fornecer o embasamento teórico que os estudantes necessitarão para realização de pesquisas científicas, possibilitando ao estudante diferenciar e elaborar os diferentes tipos de pesquisa, adequados às normativas e exigências especificas de trabalhos de natureza cientifica.

O TCC no IFMT Campus Confresa é uma disciplina ofertada no $8^{\circ}$ semestre, de caráter obrigatório, com a carga horária semestral de 160 horas. A ementa da disciplina de TCC visa motivar e nortear a escrita de teor científico, envolvendo todos os processos necessários para este trabalho de pesquisa, como apresentação de temáticas viáveis, que possam trazer benefícios para área de pesquisa. A escolha do orientador e tema de pesquisa, desenvolvimento da pesquisa norteando todas suas etapas, como no levantamento bibliográfico, acompanhamento de cronograma das atividades, coleta de dados, avaliação das versões do TCC e apresentação final para a banca avaliadora.

Para o desenvolvimento do TCC, o estudante pesquisa temáticas de sua escolha e pertinentes à sua área de atuação, contando com auxílio de um professor orientador para sua elaboração e que deverá ser apresentado em sessão pública no final do $8^{\circ}$ semestre. O TCC necessita ser escrito em Língua Portuguesa, seguindo as normas da ABNT, bem como as normas da IES e socializado como a sociedade acadêmica e aos membros da banca examinadora, previamente escolhidos pelo estudante e orientador.

"Pode-se perceber que há uma preocupação para que o TCC seja parte de um processo maior e não apenas um momento específico, isolado e estanque do Curso de Graduação" (IFMT, 2014). Nesse sentido, a IES garante dar o suporte na elaboração do TCC desde os primeiros períodos, incentivando nas pesquisas bibliográficas que deverão fazer no decorrer do curso, assim como no estímulo a participação em atividades de caráter científico, realizado no Campus, ou em eventos externos.

\section{Procedimentos Metodológicos}

Metodologicamente, o presente estudo se aproxima do estudo de caso "por desejar entender um fenômeno do mundo real e assumir que esse entendimento provavelmente englobe importantes condições contextuais pertinentes ao seu caso", uma vez que foi feito um estudo com estudantes de licenciatura de um campus específico (Yin, 2015, p. 17).

Segundo conceitua Menezes et al. (2019) a pesquisa são ações metódicas, que seguem procedimentos anteriormente definidos atendendo a um método fundamentado na razão, com a finalidade de encontrar solução e respostas de um determinado problema que foi apresentado anteriormente.

A pesquisa é a busca por determinado conhecimento, que procura as informações mais recentes sobre o tema, formulando questões de pesquisa que utilizam um projeto que propicia as respostas (Guedes \& Guedes, 2012). De acordo com 
Gil (2008, p. 27) para um conhecimento ser considerado científico deve-se "[...] determinar o método que possibilitou chegar a esse conhecimento".

Há vários tipos de pesquisa, sendo estes classificados e nomeados de diferentes formas, conforme a abordagem, o objetivo, a metodologia e procedimentos de coleta de dados. Este trabalho de pesquisa seguirá o percurso metodológico, quanto à abordagem da pesquisa que será respaldado por Flick (2013), com respeito ao objetivo da pesquisa será retratado por Gil (2008), em relação ao método será embasado na teoria de Pradanov \&Freitas (2013) e acerca do procedimento de coletas de dados serão sustentados por Gil (2008).

Inicialmente, Flick (2013) classifica a pesquisa de acordo com o tipo de abordagem: a quantitativa, a qualitativa e a mista. A percepção dos estudantes sobre os desafios da elaboração de seus TCC, não pode ser mensurada em números. Pois buscamos conhecer a causa, compreendendo os desafios da elaboração do TCC do ponto de vista dos estudantes, sendo assim a pesquisa é caracterizada como qualitativa.

No que tange aos objetivos da pesquisa, Gil (2008) distingue em exploratória, explicativa e descritiva. Tendo em vista o objetivo de levantar opiniões, conduta e crenças sobre os desafios dos licenciandos na escrita do TCC, esta pesquisa tem o intuito descritivo.

Quanto ao meio metodológico Pradanov \& Freitas (2013) discorrem sobre o método dialético, indutivo, dedutivo, hipotético-dedutivo e fenomenológico. Esta pesquisa aborda uma lacuna no conhecimento científico em relação ao parecer dos estudantes de licenciatura do IFMT Campus Confresa sobre os desafios na elaboração do TCC, no qual descrevemos o problema de forma clara e precisa, a fim de possibilitar a identificação de outros conhecimentos relevantes ao problema em questão, dessa forma essa se define como uma pesquisa de método hipotético-dedutivo.

Por fim, no que é relativo ao procedimento de coletas de dados, Gil (2008) categoriza a pesquisa levantamento de campo, tendo em consideração que essa pesquisa utiliza de dados e informações sobre características e ações dos estudantes e egressos dos Cursos de Licenciatura do IFMT Campus Confresa, sendo os representantes da pesquisa alvo sobre os desafios da escrita de TCC, essa pesquisa dispõe de coleta de dados primários. Para o acesso a esses dados primários optamos pelo método Survey, em que Gil (2008 p. 55) explica que esta pesquisa de levantamento de campo "se caracteriza pela interrogação direta das pessoas cujo comportamento se deseja conhecerem".

O instrumento de coleta de dados foi um formulário elaborado no Google Forms e encaminhado aos estudantes e egressos de Cursos de Licenciatura da IES. As questões objetivam a solução de três objetivos, o primeiro buscar o perfil dos investigados, o segundo afinar as percepções e conjecturas dos licenciandos sobre a elaboração do TCC e a terceira é estender por meio do campo outros, a investigação sobre a opinião dos sujeitos participantes sobre a elaboração do TCC.

Integraram essa pesquisa 16 estudantes concluintes e 14 egressos dos Cursos de Licenciatura do IFMT Campus Confresa, em que responderam ao formulário disponibilizado pelo link, em aplicativos de rede sociais no mês de fevereiro de 2021. Todos os investigados foram informados do teor da pesquisa bem como da garantia de participação voluntária e de caráter anônimo, e todos os sujeitos que participaram dessa pesquisa concordaram com o Termo de Livre Consentimento e Esclarecido.

Para garantir o anonimato dos sujeitos, os identificamos com códigos alfanuméricos, como L1, L2, e assim respectivamente, para os licenciandos que ainda não concluíram o curso, e E1, E2 nesta ordem, para os egressos, ou seja, estudantes que já concluíram o curso.

No formulário, foi indagado se os sujeitos participantes aceitariam ou não contribuir com a pesquisa, todos os 30 investigados, de forma unânime aceitaram a sua participação na pesquisa. Seguindo a está pergunta foi sugerido que os investigados que optassem por saber mais sobre esta pesquisa, deixassem o seu endereço eletrônico, no total 18 sujeitos participantes deixaram o endereço eletrônico, demonstrando interesse em saber sobre os resultados dessa pesquisa. 
A pesquisa utilizou-se de formulário online, em que foi disponibilizado aos sujeitos participantes um link da web, que foi viabilizado pelo Google Forms, um aplicativo que é consentido à criação e distribuição de formulários. O compartilhamento desse link foi encaminhado aos discentes e egressos de Licenciaturas do IFMT Campus Confresa, mediante aplicativo de rede social.

O formulário ficou disponível para acesso durante 10 dias, no início do mês de fevereiro de 2021. Foi encaminhado o formulário somente aos estudantes de Licenciaturas do IFMT Campus Confresa que estavam no período em que é feito o TCC, ou seja, no $8^{\circ}$ semestre, e para os egressos destes cursos da IES, totalizando 30 sujeitos que responderam ao formulário.

Ao total foram feitas 26 perguntas, sendo 21 fechadas, na qual os investigados escolhem entre as alternativas criadas pelos autores, e 05 abertas, em que requer do investigado a construção e descrição de sua própria resposta, a maioria das perguntas fechadas tiveram a alternativa "outros", em que o investigado poderia descrever sua opinião, quando a sua resposta não estava entre as opções.

Convêm destacar que o formulário foi submetido previamente ao um pré-teste, que foi exercido por uma professora doutora dos cursos de Licenciaturas e por quatro estudantes de Licenciatura, que averiguaram a confiabilidade e conteúdo das questões. Após essa avaliação, o formulário foi aprimorado de acordo com as ponderações deles.

Primordialmente, às cinco primeiras questões foram aplicadas para conhecer características do perfil dos sujeitos participantes, sendo elas: curso de Licenciatura, ano de ingresso e conclusão do curso, faixa etária e em que fase o estudante e o egresso estão no processo da elaboração do TCC. As demais perguntas foram relacionadas diretamente ao objeto de investigação.

A metodologia para discussão dos resultados será tratada da seguinte forma: os dados oriundos de perguntas fechadas seguem apresentados quantitativamente, pela frequência ou por gráficos; já os dados advindos de perguntas abertas, foi realizada a análise comparando com situações análogas à temática da pesquisa, por meio do estabelecimento de relações com o referencial teórico utilizado para embasar o estudo.

\section{Resultados e Discussão}

Com os dados coletados, primeiro fez-se a análise do perfil dos sujeitos da pesquisa, sendo a maioria deles, 13, cursam ou cursaram a Licenciatura em Ciências da Natureza com habilitação em Química, seguido de 09 dos investigados do curso de Licenciatura em Física e 08 do curso de Licenciatura em Biologia.

Nos PPCs de todas às três Licenciaturas do IFMT Campus Confresa, o número de vagas disponibilizadas anualmente são as mesmas, 20 ao total para cada curso de licenciatura, na qual até o quarto semestre as turmas são mescladas, e o curso é ofertado no período noturno (IFMT, 2014).

A Figura 1 apresenta o ano de ingresso e ano de conclusão ou previsão de conclusão de seus cursos. 
Figura 1. Ano de ingresso versus o ano de conclusão ou previsão de conclusão dos cursos de Licenciaturas.

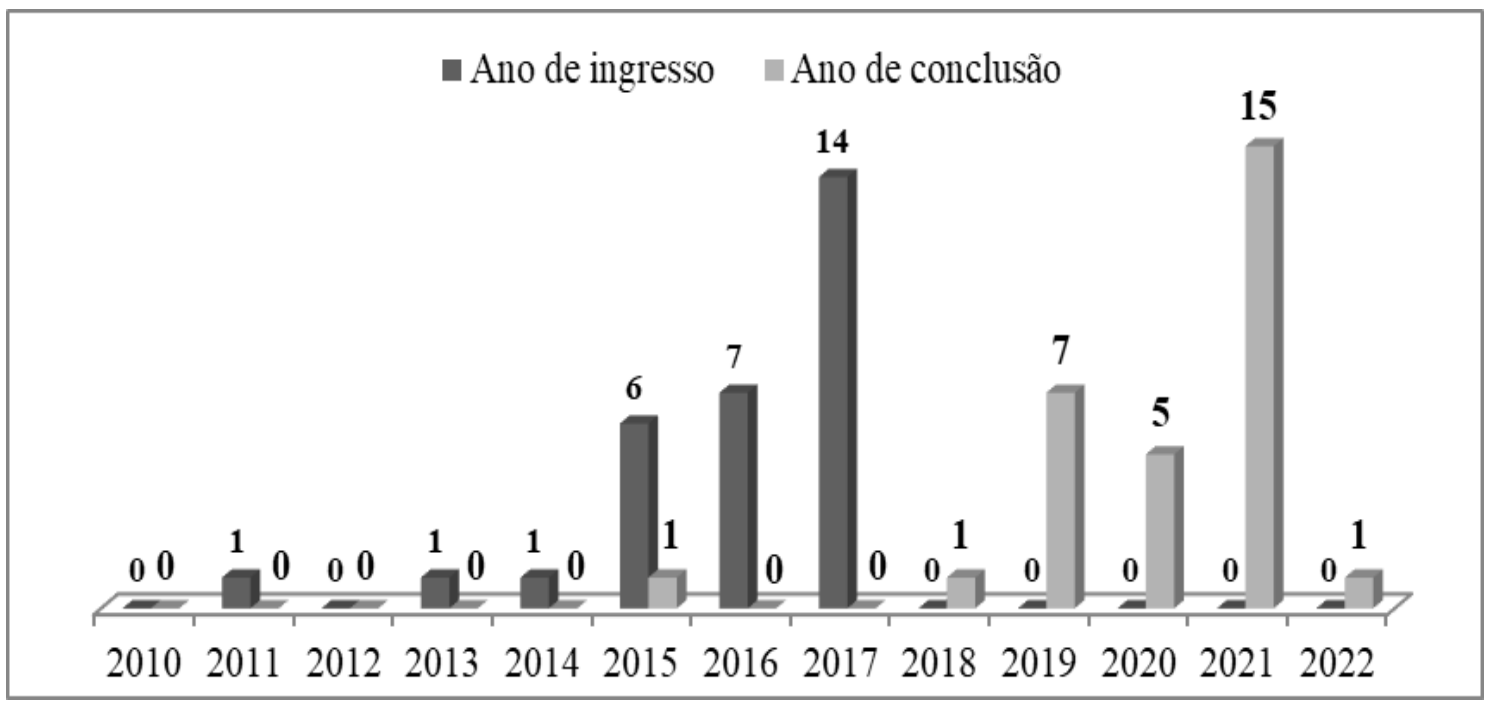

Fonte: Dados coletados na Pesquisa (2021).

Todos os cursos de Licenciaturas possuem a duração de 4 anos, porém os cursos de Física e Biologia iniciaram as primeiras turmas somente em 2015, e o curso de Ciências da Natureza com Habilitação em Química, mesmo tendo iniciado suas atividades em 2010, somente a partir de 2015, com a reformulação do PPC, passou a ser obrigatório o TCC. Anteriormente, as turmas deste curso faziam o relatório de estágio e defendiam para uma banca. Portanto, as primeiras defesas de TCC para ambos os cursos foram ocorrer em 2018.

Sobre a faixa etária dos investigados, 18 possuíam idade entre 17 e 21 anos quando entraram nos cursos de Licenciatura, seguido de 04 nas idades de 22 a 26 anos ao entrarem na graduação, apenas 01 ingressou com 27 anos e os outros 07 com 30 anos ou mais. Percebe-se que a faixa etária de ingresso nos cursos é relativamente baixa, ou seja, não são pessoas que ficaram muito tempo sem estudar.

Outro questionamento realizado foi sobre "Qual a primeira coisa que vem na sua mente quando se fala em TCC?”. Para melhor análise, optou-se por fazer uma nuvem de palavras com as concepções mais recorrentes entre os estudantes concluintes e egressos, como podemos observar na Figura 2. 
Figura 2. Nuvem de palavra com as concepções prévias sobre TCC.

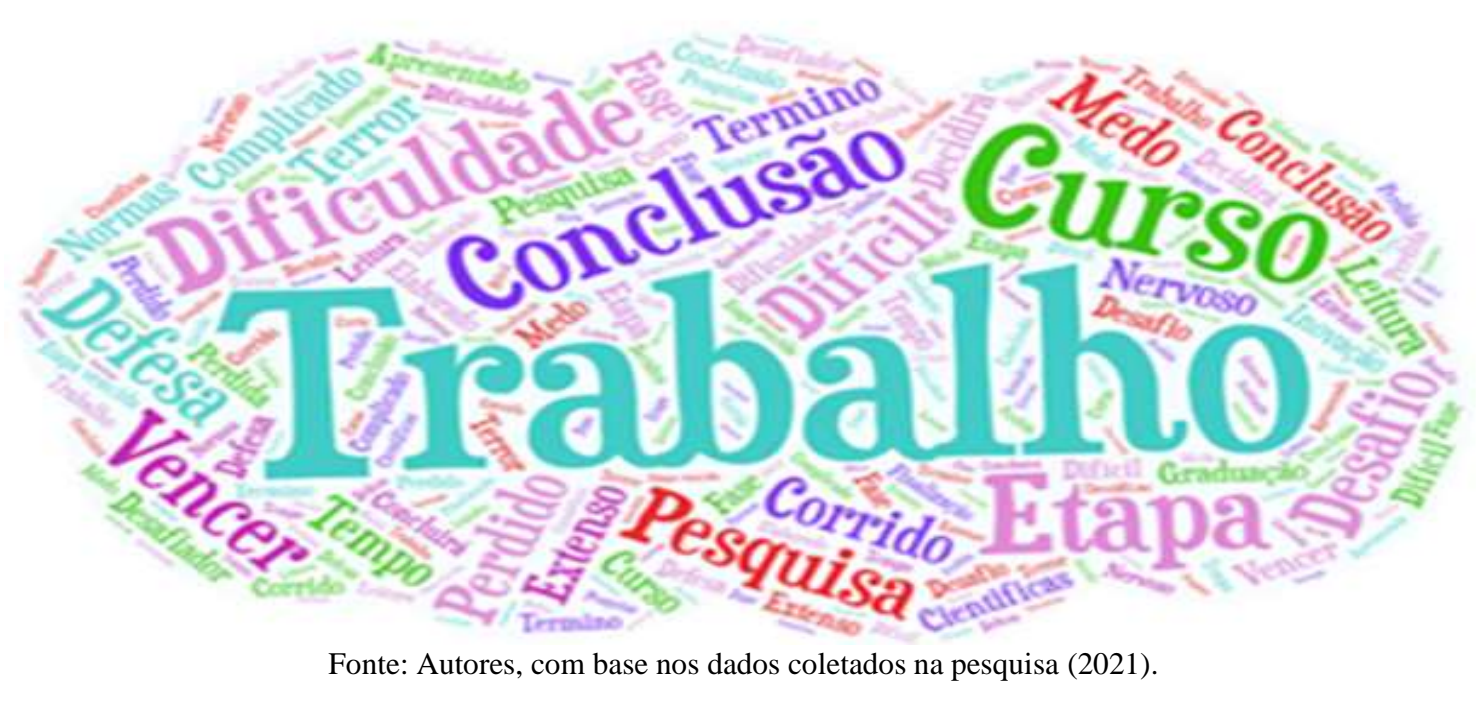

Também mencionaram frases, sendo uma delas a que L1 descreveu: "Se eu não fizer, estará tudo perdido". Percebe-se que as palavras mais mencionadas foram: trabalho, curso, conclusão, pesquisa, etapa, vencer, dificuldade entre outras. Fica evidente a preocupação deles em realizar o TCC, uma vez que da aprovação deste depende a colação de grau do licenciando. Dessa forma, Guedes \& Guedes (2012) descreve que para fazer o TCC o estudante necessita ter muita perseverança, comprometimento e executar cada etapa do método escolhido de forma correta.

O estudante denominado E1 tem outra visão sobre o TCC, descrevendo a palavra "Inovação", é certo que o trabalho de TCC, necessita de muita leitura, revisões, e pesquisa para se desenvolver um trabalho inédito e relevante. Nesse sentido, o TCC é uma maneira para o estudante estabelecer as habilidades aprendidas no curso de graduação, que são evidenciadas no desenvolvimento do mesmo (Neves \& Russi, 2007).

A última questão que versa sobre as características do perfil dos investigados é sobre em que fase de elaboração do TCC ele se encontra. Pela análise das respostas, 15 investigados já concluíram o seu TCC, 11 estão em fase de elaboração e somente 4 que precisam fazer, mas ainda não fizeram. Isto é um fator relevante, posto que a maioria dos investigados finalizaram o TCC, indicando que estes são egressos dos cursos de Licenciatura.

Os egressos já passaram por todos os possíveis contatos com a realização de pesquisa, já vivenciaram a elaboração e defesa do TCC e isso provavelmente influencia na percepção sobre o tema da pesquisa, enquanto os estudantes que ainda precisam passar por essa etapa têm mais dificuldades em argumentar sobre o assunto. Como foi exposto anteriormente a caracterização do perfil dos investigados, as próximas questões fazem referência direta ao tema de pesquisa.

A primeira questão para aprofundar mais e conhecer sobre o objeto de pesquisa, indaga aos investigados se eles se sentem preparados para a elaboração e defesa do TCC. Entre os sujeitos, 13 disseram estar preparados para elaborar e defesa do TCC, em contraste com 10 que disseram não se sentirem preparados e 7 responderam talvez. Essa sensação de sentir-se preparado deve-se as participações em eventos de cunho científico, um exemplo é o SIC, em que a cada semestre os estudantes têm que elaborar um resumo simples oriundo de uma pesquisa e apresentar oralmente para todos os acadêmicos do período noturno, as suas observações sobre diversos temas, relacionado com sua área de estudo.

Além do mais, na IES são ofertadas oportunidades de participação em programas e projetos de pesquisa, a exemplo do Programa Institucional de Bolsa de Iniciação à Docência (PIBID), financiado pela CAPES, do Programa de Incentivo à Docência (PID), financiado pelo IFMT, Projetos de Pesquisa de Editais com fomento interno ou externo à IES, além dos eventos científicos de natureza científica. Esses programas, projetos de pesquisa e eventos, são importantes, pois estudante 
com melhor capacidade de expressar informações com embasamento, e com habilidade de análise e leitura de trabalhos científicos se sobressaem sobre outros (Guedes \& Guedes, 2012).

Em conformidade com as nossas análises, os sujeitos responderam uma questão relacionada ao período de graduação e algum curso, orientação ou disciplina que os auxiliasse na elaboração do TCC, e 23 afirmaram que sim, em contraposição com 03 investigados que afirmaram não ter esse auxílio durante a sua graduação e 4 que responderam talvez.

A outra questão vem ao encontro da anterior, pois no primeiro semestre a disciplina de MTC é ofertada. Essa disciplina traz os embasamentos, normas e formas de se fazer ciência, entre eles o TCC para a realidade do licenciando. As disciplinas como MTC, possuem como objetivo a utilização de regras para sistematizar a pesquisa no decorrer da graduação, levando em consideração a busca pelo conhecimento e o amadurecimento profissional por meio do sistema de pesquisa (Maia, 2008).

A questão para aprofundamento foi se a disciplina de MTC auxiliou de alguma forma com elaboração do TCC. Foram 20 investigados alegando que a disciplina contribuí para a elaboração do TCC, em oposição 03 investigados demonstram que a disciplina não contribuiu para o desenvolvimento do TCC e 7 não se posicionaram.

Questionamos também sobre a preferência dos licenciandos a respeito da disciplina de MTC, em relação a sua oferta, uma vez que a elaboração de TCC é no final do curso e a disciplina que auxiliará nessa construção está no primeiro semestre. Conforme constatamos na Figura 3, os 18 licenciandos afirmaram que a MTC deveria ser ofertada no $8 .^{\circ}$ semestre, que é ao final do curso, contra 13 que prefeririam que esta disciplina fosse ofertada de maneira gradativa no decorrer do curso. Apenas um investigado manifestou sua opinião com a alternativa outros, dispondo que deseja continuar como está, na qual a disciplina é ofertada no início do curso.

Figura 3. Preferencias em relação à oferta da disciplina de MTC.

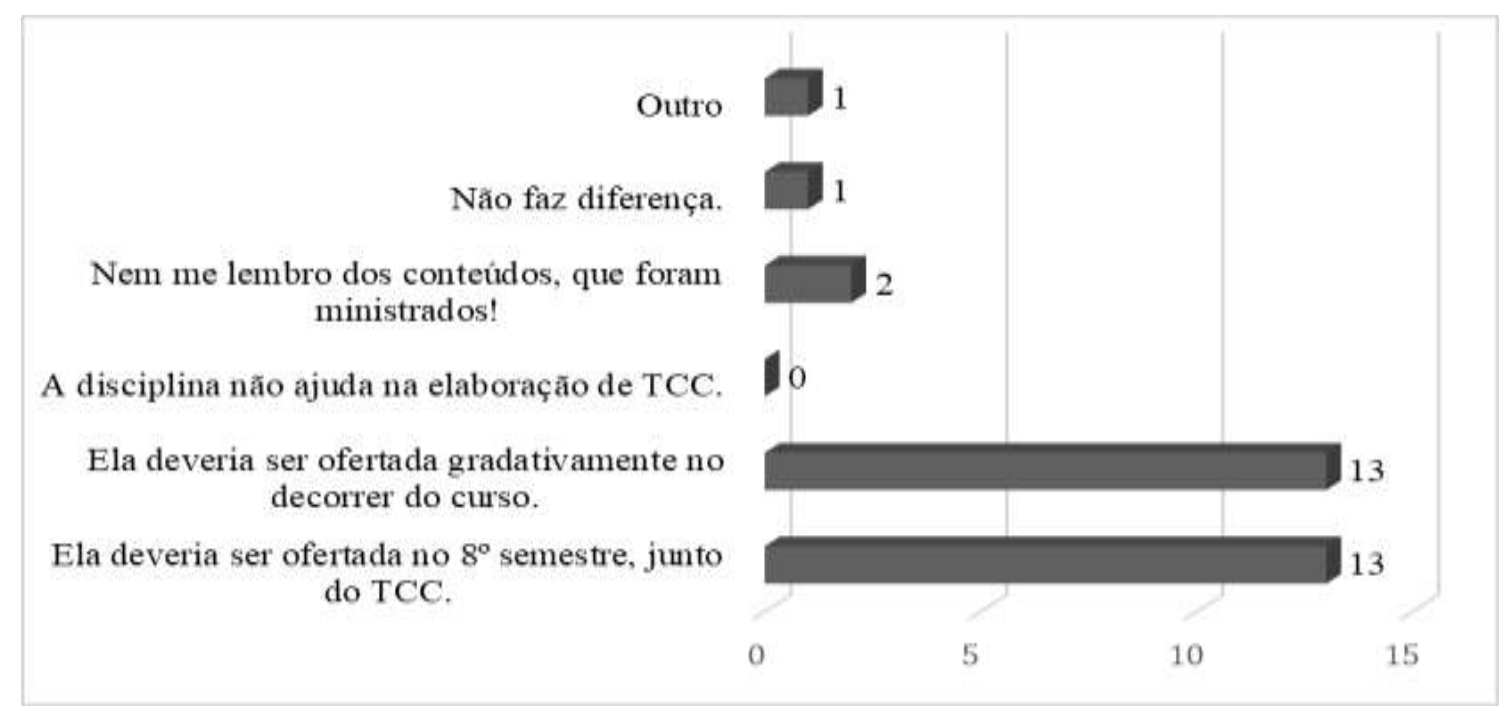

Fonte: Dados coletados na Pesquisa (2021).

Segundo consta nos PPC dos cursos (IFMT 2014), uma das finalidades da disciplina de MTC é "“...] a elaboração de trabalhos científicos, introduzindo os estudantes no universo da produção científica". Dessa maneira, a disciplina como consta nas questões anteriores auxilia na construção do TCC, então caberá a IES verificar a necessidade de mudanças.

As próximas duas questões irão versar sobre os Licenciandos que estão fazendo o TCC, nesse momento de pandemia, que começou desde 2019. Essa questão foi direcionada aos estudantes que estão em fase de elaboração de TCC, deixando claro essa restrição aos demais investigados. 
Foi abordado ao investigado sobre como está sendo a elaboração do TCC nesse momento pandêmico, e 14 apontaram que está sendo difícil, em contrate, 01 investigado afirma estar sendo fácil a elaboração do TCC em meio a pandemia, como percebemos na Figura 4.

Figura 4. Sobre a elaboração do TCC em período de pandemia.

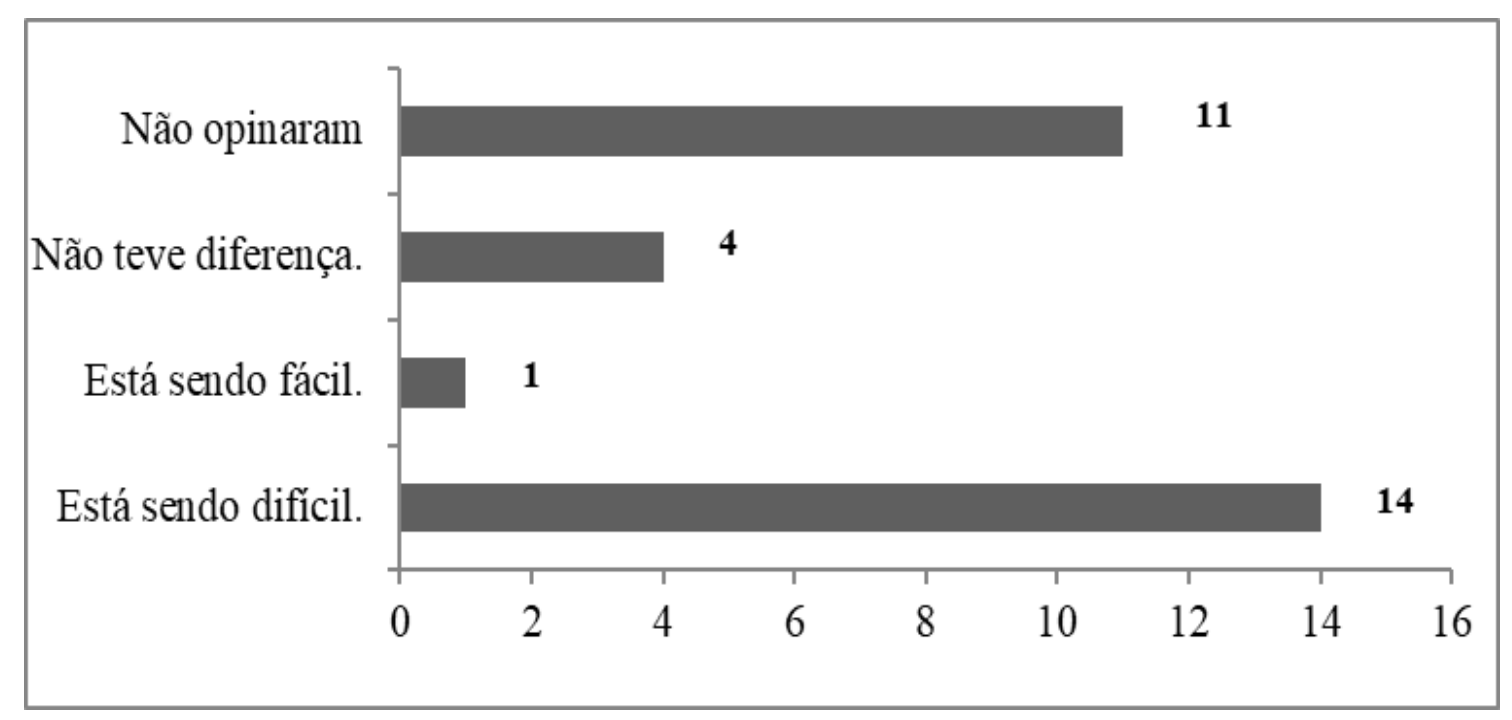

Fonte: Dados coletados na Pesquisa (2021).

Percebe-se que a elaboração do TCC está sendo difícil para ampla maioria dos respondentes. Provavelmente o isolamento social limita alguns elementos facilitadores para a construção do TCC, tais como a relação direta com o orientador, conforme menciona Guimarães e Silva Sobrinho (2020).

A seguinte questão corrobora com a predecessora, nesta foi solicitado aos Licenciandos que descrevesse o maior desafio diante da atual situação, na elaboração do seu TCC. Essa questão foi aberta e coletamos às duas principais opiniões.

O investigado L1 disse que o maior desafio é o "Referencial teórico e discussão dos resultados", o L2 afirma que é o "Distanciamento do orientador e da instituição", o L3 relatou que sua dificuldade será a "Defesa online, pois gostaria que fosse presencial", o L4 destaca que "Não ter contato direto com o orientador, e também não poder realizar pesquisas presencias" é a maior dificuldade.

Em discordância com as demais respostas, o L4 alega que "Com pandemia ou sem pandemia, estruturar um TCC de forma coesa será sempre difícil" e o L5 que reforça "O problema não é a pandemia, mas a pouca instrução de como elaborar um TCC". Em tempos de pandemia, Souza (2020) destaca que a educação precisa se reinventar.

Para diminuição dos efeitos da pandemia da Covid-19 na educação, as escolas do mundo tiveram de fechar as portas físicas e encarar as portas do mundo digital, que como solução temporária optou-se pelo ensino remoto (Melo, 2020).

Perguntamos sobre a relação com o orientador (a), sendo que dos 30 que responderam 20 investigados assinalaram que o orientador está lhe ajudando em tudo o que precisa. Essa questão foi condicionada aos estudantes que já concluíram, e aos que estão elaborando o seu TCC. Resultados apresentados na Figura 5. 
Figura 5. Sobre a participação do seu orientador.

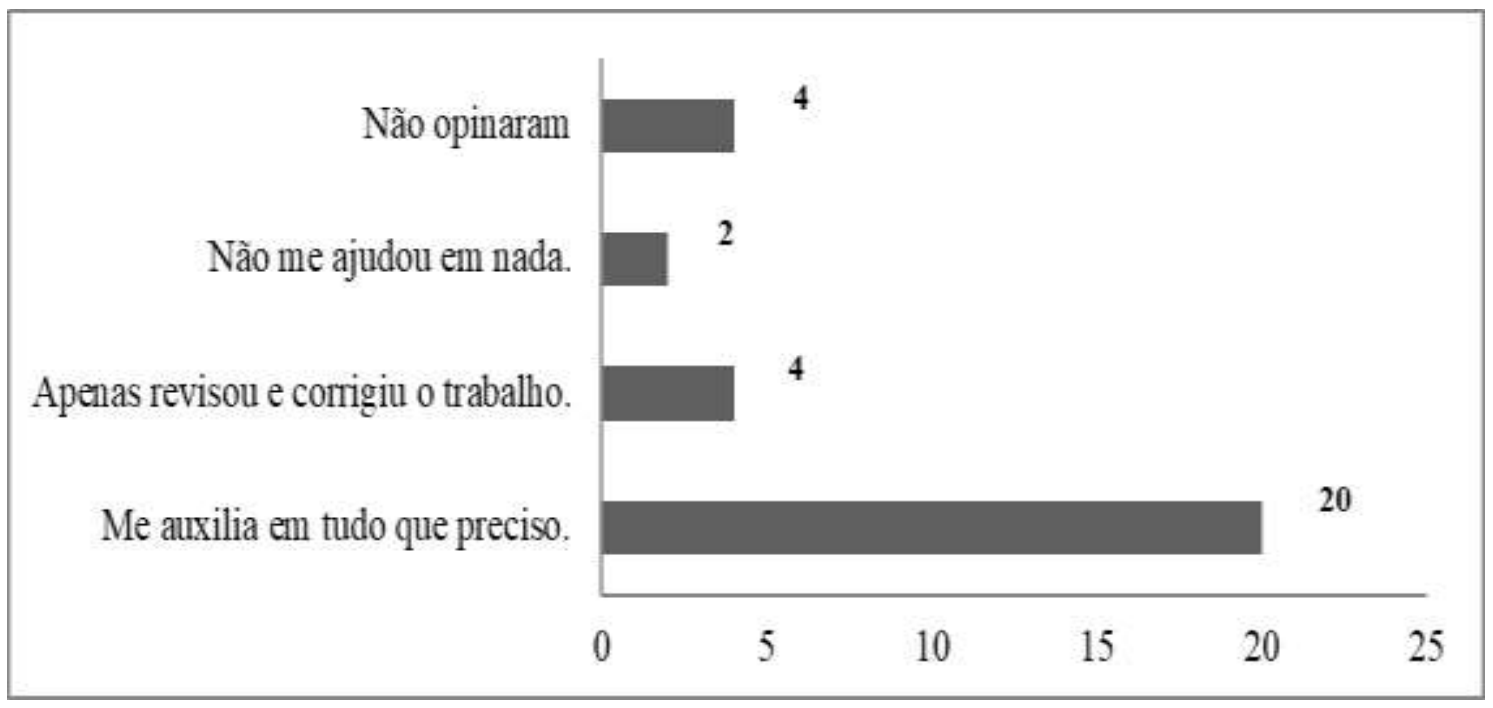

Fonte: Dados coletados na Pesquisa (2021).

Esses resultados são corroborados por Carboni e Nogueira (2004), que afirmam que no momento que o estudante tem um orientador presente, o método de escrita torna-se compreensível ao estudante, e todo o processo é facilitado, pois o orientador o guia na direção certa. No entanto, o estudo de Antunes et al. (2011) evidenciou que muitos estudantes que não se saíram bem em seu TCC apontam como principal causa o mau relacionamento com o orientador(a), como a demora das respostas de feedback, falta de esclarecimentos essenciais, entre outros.

$\mathrm{Na}$ sequência, verificamos as respostas dos investigados sobre a escrita e publicação de trabalhos científicos durante o curso de Licenciatura, dos quais 21 disseram ter escrito e publicado algum trabalho científico. Dos 30 respondentes, apenas 09 afirmaram não ter redigido nenhum trabalho científico. A pesquisa cientifica é fundamental para o incentivo a curiosidade e interesse de fazer seu próprio conhecimento (Guedes \& Guedes, 2012). A escrita de trabalhos científicos familiariza o licenciando, as normas e métodos que devem ser empregados no TCC.

Em conformidade com a questão anterior, somente os investigados que disseram sim a questão anterior poderia respondê-la, assim a questão é se os investigados acreditam que a escrita desses trabalhos científicos auxilia na escrita do seu TCC. Assim, 20 investigados acreditam que a elaboração de trabalhos científicos os auxiliou na escrita de seu TCC, em oposição a 01 investigado que afirma que talvez a escrita de trabalhos científicos possa ajudar na escrita do TCC, 9 deles preferiram não opinar.

No estudo de Carboni e Nogueira (2004), concluiu-se que os fatores que favorecem a elaboração de TCC, segundo a pesquisa feita com 76 estudantes de graduação em Enfermagem, é o vislumbre em aprender a realizar pesquisa cientifica, ter um orientador para compreender os processos de elaboração do TCC e escolha do tema.

A questão que seguirá, demonstraram a concordância majoritária sobre quais das opções foram as que mais contribuíram para elaboração do seu TCC, cabe salientar que dentre as alternativas o licenciando poderia marcar uma opção mais de uma vez.

Na Figura 6 podemos visualizar que a alternativa mais pontuada foram, a participação em projetos de pesquisa com 24, seguido de orientações do orientador com 23 e a 20 da disciplina de MTC, apenas 01 investigado selecionou a alternativa de outros, destacando que outros professores da IES colaboraram na escrita do TCC. 
Figura 6. Contribuições para a elaboração do seu TCC.

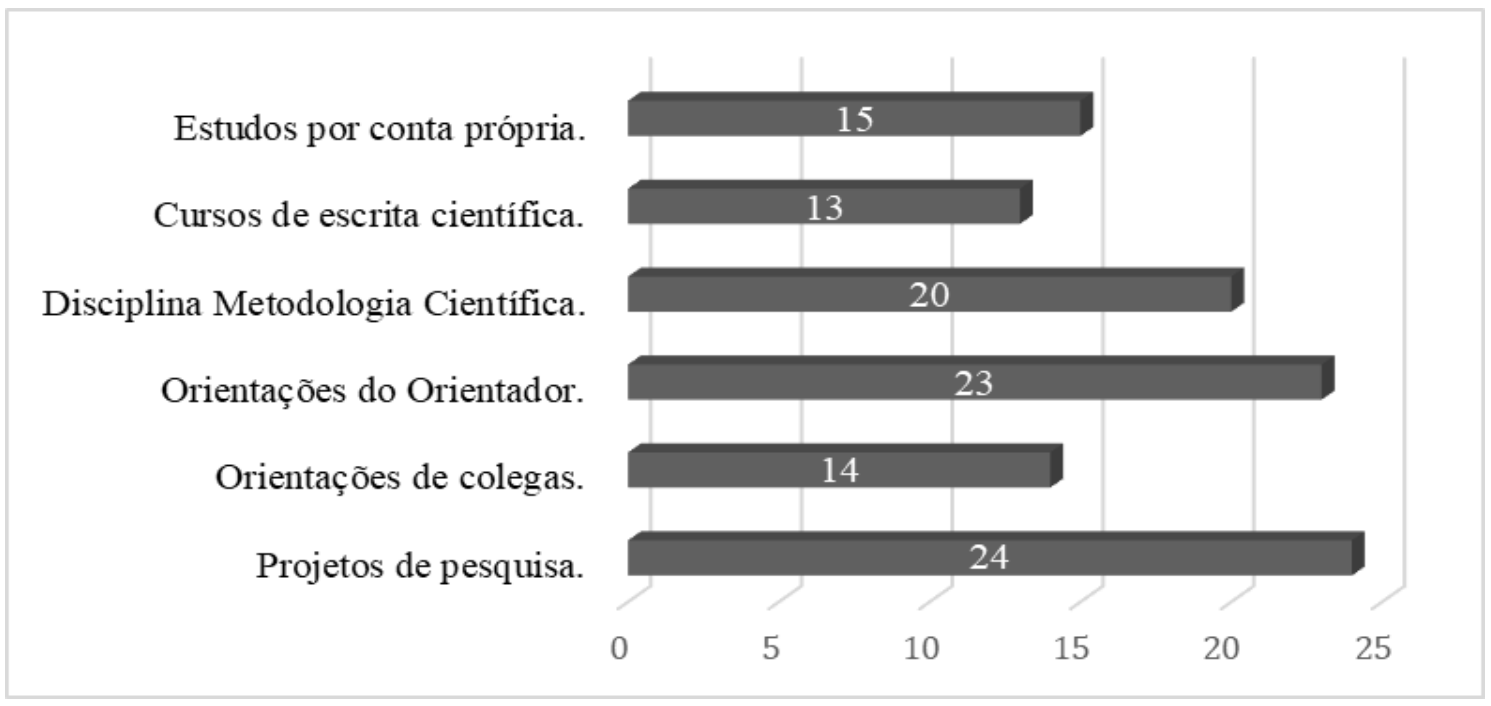

Fonte: Dados coletados na Pesquisa (2021).

Percebe-se que o envolvimento com projetos de pesquisa foi a atividade mais apontada como contribuição, seguido dos momentos de orientação e dos ensinamentos proporcionados pela disciplina de MTC. Para Silva Junior et al. (2014) a participação em projetos de pesquisa é "[...]uma oportunidade aos acadêmicos de desenvolver senso crítico, ético e profissional, com o intuito de aumentar a evidenciação científica [...]". A pesquisa de Peixoto et al. (2014) está em concordância com esta, tendo em conta que $55,1 \%$ dos seus investigados afirmaram que programas de iniciação científica que são oportunizados pela IES contribui para construção do TCC e mostra que quem participa de tais atividades aprende a desenvolver a pesquisa cientifica, aplicando esse conhecimento na escrita do TCC.

Foram abordadas questões sobre a terceirização de TCC, que infelizmente é uma realidade em IES de todo país. Na primeira questão foi questionado se o investigado conhece alguém que pagou a outra pessoa para escrever o TCC, 17 afirmou que conhece alguém que terceirizou o TCC, em paralelo á 12 que afirmam desconhecer alguma pessoa que possa ter terceirizaram o TCC, e apenas 1 respondeu que talvez.

Subsequente, dissertamos se o investigado pensou, em algum momento, em pagar para outra pessoa fazer o seu TCC. Ao total 21 manifestaram que não, 6 talvez e somente 3 evidenciaram tal pensamento. Esse assunto é ressaltado, visto que, segundo Alencar (2016) em razão de ser um problema sério que não deve ser desprezado, em que ocorre com frequência nas IES e que traz repercussões negativas. O autor também define essa atitude como plágio, que é quando uma pessoa apropria indevidamente de um trabalho, agindo como se fosse de sua própria autoria, sem dar o devido crédito e ferindo os direitos autorais da pessoa. Ademais um dos critérios para colação de grau, além da escrita, defesa do TCC, a autoria deve ser do estudante, podendo ocorrer punições como a perda do diploma, e responder por vias de processos legais.

A próxima questão foi delimitada aos investigados que responderam sim ou talvez a pergunta anterior. Essa questão foi aberta para poderemos avaliar melhor suas ponderações, dessa forma pediu-se que os investigados descrevessem o porquê desta consideração.

O sujeito participante L1 expôs "Por medo de não dar tempo, pois estava trabalhando muito", outros 5 investigados indicaram o mesmo problema, a falta de tempo. O investigado L2 destacou "Não me sinto preparado para elaborar um trabalho tão importante assim", e o E2 "Porque a cada correção parecia mais impossível de finalizar o TCC".

Na questão seguinte, verificamos se os licenciandos conheciam alguma pessoa que desistiu do curso de licenciatura por causa das dificuldades na elaboração do TCC. Ao total 13 disseram não conhecer, contra 17 que disseram conhecer, sendo 
que 5 sujeitos participantes argumentaram que conhece algum estudante que evadiu, mas que depois de algum tempo voltou e conseguiu concluir o TCC.

A Figura 7 expõe os maiores desafios considerados pelos investigados na elaboração do TCC, 19 investigados alegaram ser a escrita científica do TCC como maior desafio, seguido de 17 investigados mencionam ser a falta de tempo para conciliar as atividades do curso com outros compromissos como trabalho.

Figura 7. Dificuldades na elaboração do TCC.

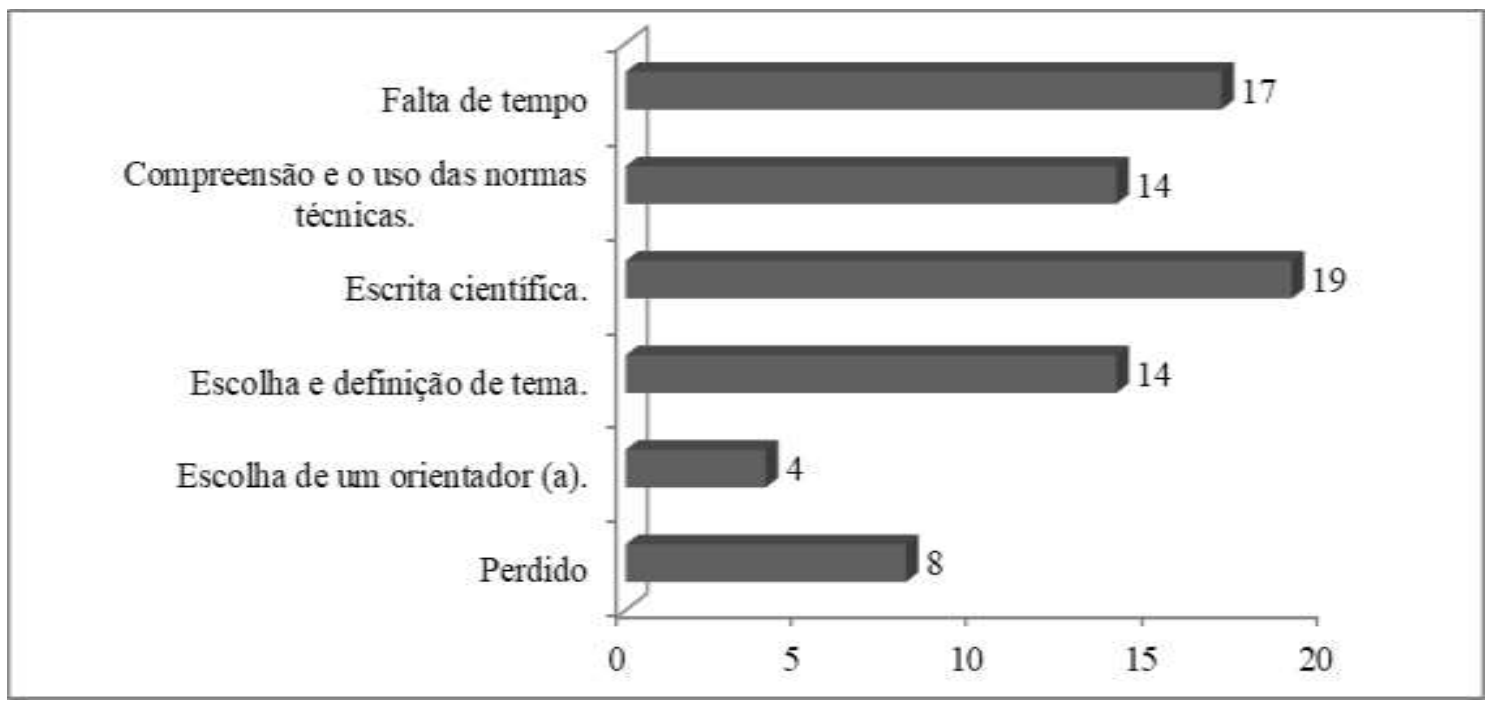

Fonte: Dados coletados na Pesquisa (2021).

O fator apontado como maior entrave, ou seja, maior dificuldade para a elaboração do TCC foi o exercício da escrita científica. Mezencio (2018) aborda que por mais que o TCC seja de suma importância para a construção da pesquisa e habilidade para os estudantes, ainda sim a elaboração do TCC é uma tarefa extremamente difícil. Em congruência Carboni e Nogueira (2004) evidenciam como principais dificuldades à falta de tempo, os custos do trabalho, e a procura de um orientador (a). O tempo é por causa dos trabalhos em paralelo à graduação, os custos por falta de recursos como computador, e em relação ao orientador é a falta de tempo dos mesmos.

Á também a contribuição de Ramos, Bianchi e Vendrusculo (2016) reconhecem que a "[...] dedicação do aluno, a relação teórico/prática do tema e o conhecimento técnico e profissional dos professores" são os maiores percalços na elaboração do TCC. Guimarães e Silva Sobrinho (2020) concluíram em suas pesquisas que os fatores que dificultam a elaboração do TCC são mudança de orientador, tema que não é escolhido pelo estudante e sim pelo orientador, o acervo da biblioteca, o tempo e o custo da elaboração do TCC.

Questionamos os investigados se acreditam que o TCC contribui de alguma forma para sua atuação profissional. Dos quais 22 consideram que a elaboração do TCC irá contribuir na carreira profissional, 2 entendem que não e 6 não opinaram. Esse resultado positivo pode ser em virtude da carreira profissional ser acadêmica, que diferente de outras profissões detém a pesquisar e trabalhar mais com a produção científica.

Em oposição à pesquisa de Ramos, Bianchi e Vendrusculo (2016), que foi realizado com estudantes de Ciências Contáveis das Universidades Federais do Rio Grande do Sul, também foram questionados, se houve alguma mudança na carreira profissional após a elaboração e defesa do TCC, e grande parte dos estudantes expressaram que houve nenhuma mudança.

A questão que segue versou sobre a obrigatoriedade do TCC, e foi questionado se o TCC não fosse obrigatório, se 
eles o fariam, 12 investigados assumiram que não e os 9 disseram que sim e 9 não se posicionaram. É certo que a maioria dos estudantes não sabe sobre o que pretendem realizar no TCC, e para muitos estudantes é a única atividade científica que eles irão realizar, e a obrigatoriedade do TCC retira a escolha pela pesquisa (Silva Junior et al., 2014).

$\mathrm{O}$ autor supradito destaca em sua pesquisa que houve divergência entre os seus resultados, de um lado estudantes que defendiam a obrigatoriedade do TCC, justificando ser um facilitador do conhecimento científico e de outro os que acham desnecessário essa obrigatoriedade, pois é apenas mais um trabalho para o currículo acadêmico.

Por fim, a última questão solicitou que os investigados externassem em poucas palavras a sua opinião sobre quais seriam as suas sugestões para melhorar a experiência de elaboração do TCC. Para melhor visualização evidenciamos na Figura 8 , uma nuvem de palavras referente às sugestões dos investigados.

Figura 8. Nuvem de palavra com as sugestões para melhorar a elaboração do TCC.

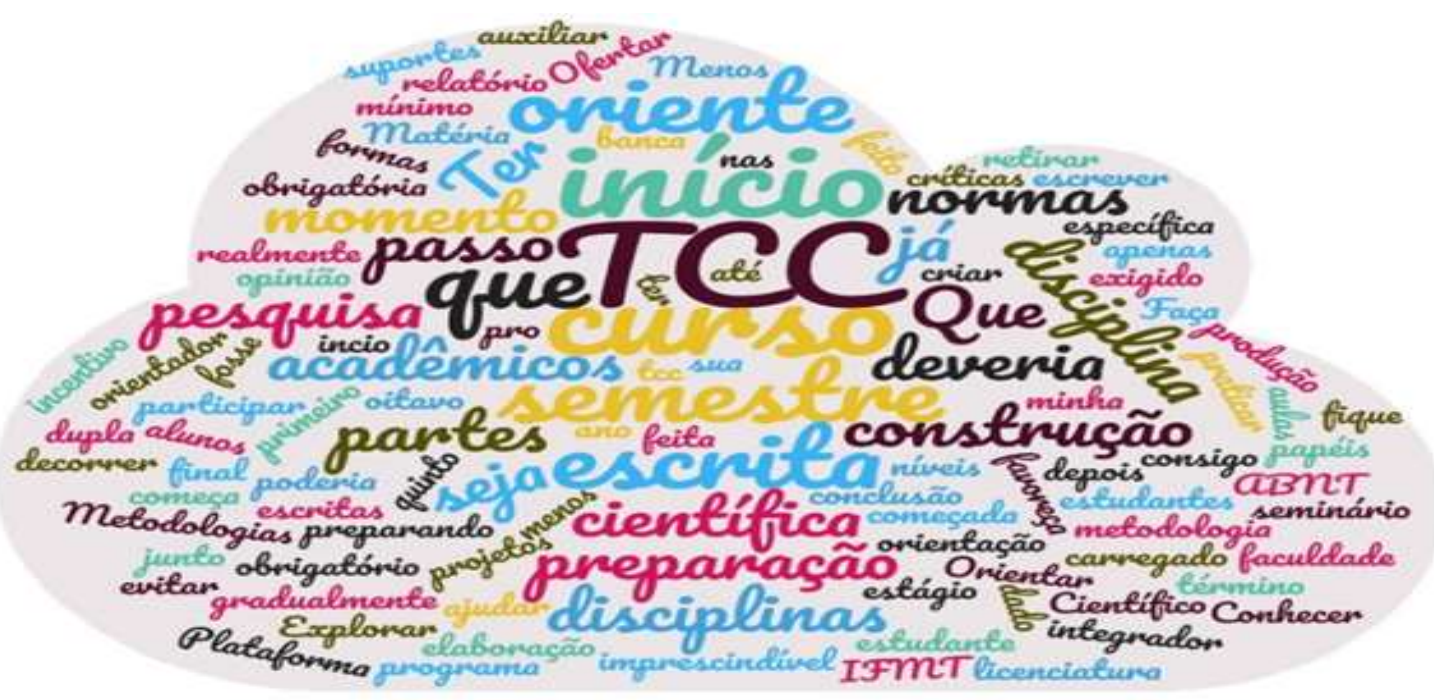

Fonte: Autores, com base nos dados coletados na pesquisa (2021).

A pergunta foi aberta, e todos os investigados enunciaram suas sugestões, em que destacamos algumas sugestões, como a do sujeito participante L1 na qual enfatiza "Que deveria ser obrigatório desde o início do curso a construção do TCC. Assim poderia ser feito em partes", o E1 destacou que "Não vejo o TCC como forma de punição, ou trabalho com grau de dificuldade maior que a habilidade dos estudantes. Acredito que o TCC desenvolve as pessoas para o meio", o investigado E2 sugere aos estudantes que "Façam o TCC antes do término da faculdade, para evitar imprevistos depois".

O investigado E3 alega que "Trabalhar a disciplina MTC no decorrer do curso, explorar mesmo as normas da ABNT, conhecer e praticar a escrita científica são imprescindíveis; muitos estudantes chegam ao final do curso com essa defasagem, sentem muita dificuldade na elaboração do TCC e até mesmo nos Relatórios de Estágios Curriculares Supervisionados, observei isso, quando estudava".

O sujeito participante E4 sugere "[...] Desde início já ir preparando os acadêmicos para a elaboração TCC, principalmente, ofertar oportunidades para participar de projetos, isso fará a diferença na hora de escrever". Logo, as sugestões mais frequentes entre as respostas foram à oferta de uma disciplina e/ou curso desde o início da graduação até a defesa, ou seja, gradativo.

De maneira geral, as percepções destes estudantes concluintes ou egressos esclarecem como o TCC é compreendido e desenvolvido durante o processo formativo, além de confirmar alguns aspectos já apontados por Antunes et al. (2011), Guedes e Guedes (2012) e Guimarães e Silva Sobrinho (2020), sobre a importância deste ato científico para a vida acadêmica e 
profissional.

\section{Considerações Finais}

O TCC é considerado por muitos estudantes, um desafio, visto que sua elaboração exige um trabalho de cunho científico, e que mediante a aprovação deste depende a conquista do diploma. A realização deste estudo possibilitou compreender os desafios na elaboração do TCC, por meio da descrição das percepções dos estudantes concluintes ou egressos dos Cursos de Licenciatura do IFMT Campus Confresa.

Os principais desafios na elaboração do TCC percebidos pelos licenciandos foram à escrita científica e a dificuldade de conciliar o tempo de escrita com outras atividades. Os pontos positivos sobre a elaboração do TCC apontados pelos investigados foi que a escrita de projetos de pesquisa e a disciplina de MTC auxiliaram na elaboração do TCC, ademais defenderem que o desenvolvimento do TCC contribui de maneira significativa para a vida profissional.

Uma das limitações desta investigação foi que a amostra está inserida no contexto dos Licenciandos do IFMT Campus Confresa, não podendo ser generalizada para outros cursos e até mesmo para outras IES. Outra limitação é a escassez bibliográfica relacionada a este tema, outros estudos são necessários para colaborarem com os dados dessa pesquisa.

Mediante ao exposto, ressaltamos que a hipótese apresentada foi parcialmente negada, considerando que os investigados possuem convivência com a escrita científica, por meio de atividades e eventos de caráter científico propiciado pelo IFMT Campus Confresa. A hipótese em parte foi confirmada, em relação à concepção de que os Licenciandos se sentiam confusos com dúvidas e até mesmo perdidos na elaboração do TCC.

Ao propor essa reflexão sobre os principais desafios na elaboração do TCC, os investigados puderam expor suas percepções sobre o assunto e apontar sugestões, que, de acordo com os próprios estudantes, foram decisivos para melhorar o processo de elaboração e escrita dos seus TCCs. Logo, o presente estudo contribui com a pesquisa em que verifica a importância e influência da escrita e desenvolvimento do TCC para estudantes e egressos dos Cursos de Licenciaturas em sua vida profissional, bem como verificar as percepções sobre o assunto. Futuros estudos podem abordar a relação dos orientadores com os orientandos, ou mesmo verificar como os docentes orientadores percebem as dificuldades de seus orientandos e as possibilidades de minimizar essas dificuldades.

\section{Agradecimentos}

Ao Instituto Federal de Mato Grosso (IFMT) Campus Confresa, pela formação proporcionada.

\section{Referências}

Alencar, L. B. (2016). Práticas de orientação de TCC em curso de graduação em Ciências Contábeis em IES da cidade de São Paulo que possuem Stricto Sensu. 2016. 208 f. Dissertação (Mestrado em Ciências Contábeis) - FECAP, http://tede.fecap.br:8080/jspui/handle/jspui/720.

Antunes, E. D. D., Brunneta, N., Demarco, D. J., \& Pinheiro, I. A. (2011). Desafios na construção do trabalho de conclusão do curso de especialização em negociação coletiva/modalidade à distância. RENOTE-Revista Novas Tecnologias na Educação, 9(2), 1-11. https://www.seer.ufrgs .br/renote/article/view/25140.

Associação Brasileira de Normas Técnicas - ABNT. NBR 14.724: informação e documentação - trabalhos acadêmicos - apresentação. ABNT, 2011.

Brasil. (1997). Resolução CNE/CES No 776/1997, aprovado em 3 de dezembro de 1997: Orientações para as diretrizes curriculares dos Cursos de graduação. CNE/CES. http://portal.mec.gov.br/index.php?option=com_docman\&view=download\&alias=154121-pces776-97\&category_slug=agosto-2020pdf\&Itemid=30192.

Brasil. (2001). Resolução CNE/CES N $583 / 2001$ : Orientação para as Diretrizes Curriculares dos Cursos de Graduação. Homologação publicada no DOU de 29/10/2001, Seção 1, p. 87. http://portal.mec.gov.br/cne/arquivos/pdf/pces1210_01.pdf.

Brasil. (2002). Resolução CNE/CP No 1, de 18 de fevereiro de 2002: Institui Diretrizes Curriculares Nacionais para a Formação de Professores da Educação Básica, em nível superior, curso de licenciatura, de graduação plena. Brasília: Conselho Nacional de Educação. http://portal.mec.gov.br/cne/arquivos/pdf/CP012002.pdf. 
Brunetta, N., Antunes, E. D. D., Pinheiro, I. A., \& Demarco, D. J. (2011). Desafios na Construção do Trabalho de Conclusão do Curso de Especialização em Negociação Coletiva/Modalidade a Distância. In: XXV Anpad, 2011, Anais. Rio de Janeiro. http://www.anpad.org.br/diversos/down_zips/58/EPQ2968.pdf.

Carmo, L. M., Machado, R. S., \& Cogan, S. (2015). Uma análise do processo de elaboração do trabalho de conclusão de curso a partir do processo de raciocínio da teoria das restrições. Registro Contábil, 6(3), pp. 83-99.

Carboni, R. M., \& Nogueira, V. O. (2004). Facilidades e dificuldades na elaboração de trabalhos de conclusão de curso. ConScientiae Saúde, 3, 65-72, 2004. https://www.redalyc.org/pdf/929/92900308.pdf.

Clemente, F. A. S., \& Santos, L. C. B. (2015). Desmistificando o trabalho de conclusão de curso (TCC) da graduação. Revista Educação-UNG-Ser, 10(2), 2339. http://revistas.ung.br/index.php/educacao/article/view/2159.

Costa, A. N. S., Coelho, G. R. B., Alves, A. C. T., Lopes, T. B., Cardoso, P. H. F., \& Jesus Neto, D. F. (2018). Motivos da evasão de discentes de licenciaturas do IFMT Campus Confresa. In: VII ENALIC, 2018, Campina Grande. Anais. Campina Grande: Realize Editora. http://www.editorarealize.com.br/index.php/artigo/visualizar/51504.

Flick, U. (2013). Introdução à metodologia de pesquisa: um guia para iniciantes. Penso. 392162047-Introducao-a-Metodologia-de-Pesquisa-Um-Guia-paraIniciantes-pdf.pdf - Google Drive.

Gil, A. C. (2008). Métodos e técnicas de pesquisa social. $6^{\text {th }}$. São Paulo: Atlas. gil-a-c-mc3a9todos-e-tc3a9cnicas-de-pesquisa-social.pdf - Google Drive.

Guedes, H. T. V., \& Guedes, J. C. (2012). Avaliação, pelos estudantes, da atividade "Trabalho de Conclusão de Curso" como integralização do eixo curricular de iniciação à pesquisa científica em um curso de medicina. Rev. bras. educ. med., 36(2), 162-171. http://www.scielo.br/scielo.ph p?script=sci_arttext\&pid=S0100-55022012000400003\&lng=en\&nrm=iso.

Guimarães, J. C., \& Silva Sobrinho, F. D. (2020). Fatores facilitadores e dificultadores à construção do TCC. Revista Brasileira de Administração Científica, 11(3), pp. 82-99. http://www.sustenere.co/index.php/rbadm/article/view/CBPC2179-684X.2020.003.0006.

IFMT. (2019). PPC. Projeto Pedagógico do curso de Licenciatura em Ciências da Natureza - Habilitação em Química 2019. Instituto Federal de Educação Ciências e Tecnologia de Mato Grosso - Campus Confresa: Confresa-MT.

Lakatos, E. M., \& Marconi, M. de A. (2003). Fundamentos da metodologia científica. Atlas. Lakatos - Marconi - Fundamentos De Metodologia Cientifica.pdf - Google Drive.

Lakatos, E. M., \& Marconi, M. de A. (1992). Metodologia do trabalho científico: procedimentos básicos, pesquisa bibliográfica, projeto e relatório, publicação e trabalhos científicos. Atlas. Eva Maria Lakatos \& Marina de Andrade Marconi- Metodologia do trabalho científico.pdf - Google Drive.

Maia, R. T. (2008). A importância da disciplina de metodologia científica no desenvolvimento de produções acadêmicas de qualidade no nível superior. Revista Urutágua, 14(1), 1-8.

Menezes, A. H. N., Duarte, F. R., Carvalho, L. O. R., \& Souza, T. E. S. (2019). Metodologia científica: teoria e aplicação na educação a distância- PetrolinaPE. Livro digital. https://portais.univasf.edu.br/noticias/univasf-publica-livro-digital-sobre-metodologia-cientifica-voltada-para-educacao-a-distancia/livro-demetodologia-cientifica.pdf.

Mezencio, C. e S. (2018). Determinantes da aprovação ou reprovação dos alunos de graduação em Ciências Contábeis da UnB no trabalho de conclusão de curso. 2018, 54 f., il. Trabalho de Conclusão de Curso (Bacharelado em Ciências Contábeis) - Universidade de Brasília, Brasília. https://bdm.unb.br/bitstream/10483/22697/1/2018_CarolinaSilvaMezencio_tcc.pdf.

Neves, J. M. S. das, \& Russi, L. N. (2007). O TCC como ferramenta para consolidação das competências adquiridas no ensino de tecnologia na Fatec Guaratinguetá (SP). In: Encontro de ensino e pesquisa em administração e contabilidade, I., Recife. Anais eletrônicos. EnEPQ. http://www.anpad.org.br/admin/pdf/ENEPQ415.pdf.

Peixoto, E. P. De A., França, R. D. De, Andrade, E. P. A. De, \& Menêses, F. A. F. de. (2014). A Contribuição da Iniciação Científica na Elaboração do TCC no Curso de Ciências Contábeis sob a Ótica do Corpo Discente: uma Pesquisa nas IES Públicas do Estado da Paraíba. Anais... In. In: XI Congresso de iniciação científica da USP. São Paulo. https://congressousp.fipecafi.org/anais/artigos142014/227.pdf.

Pradanov, C. C., \& Freitas, E. C. de. (2013). Metodologia do trabalho científico [recurso eletrônico]: métodos e técnicas da pesquisa e do trabalho acadêmico. $-2^{\text {th }} .-$ Novo Hamburgo: Feevale. LIVRO_PRODANOV_FREITAS_Metodologia do Trabalho Cientifico.pdf (google.com).

Ramos, M. Dos S., Bianchi, M., \& Vendruscolo, M. I. (2016). Contribuição do trabalho de conclusão de curso na formação profissional dos alunos de Ciências Contábeis das Universidades Federais do Rio Grande do Sul. $2016 . \quad$ https://www.lume.ufrgs.br/bitstream/handl e/10183/189733/001053295.pdf?sequence=1\&isAllowed=y.

Silva, E. L. da, \& Menezes, E. M. (2005). Metodologia da pesquisa e elaboração de dissertação. UFSC. Metodologia_de_pesquisa_e_elaboracao_de_teses_e_dissertacoes_4ed.pdf - Google Drive.

Silva Junior, M. F., Assis, R. I. F., Sousa, H. A., Miclos, P. V., \& Gomes, M. J. (2014). Iniciação científica: percepção do interesse de acadêmicos de odontologia de uma universidade brasileira. Saúde e Sociedade [online]. 23(1), 325-335. https://doi.org/10.1590/S0104-12902014000100026.

Souza, E. P. de. (2020). Educação em tempos de pandemia: desafios e possibilidades. Cadernos de Ciências Sociais Aplicadas, [S. 1.], 7(30), pp. 110-118. https://periodicos2.uesb.br/index.php/ccsa/article/view/7127.

Yin, R. K. Estudo de Caso: Planejamento e Métodos. (5a ed.), Bookman, 2015.

Zambello, A. V., Soares, A. G., Tauil, C. E., Donzelli, C. A., Fontana, F., Chotolli, W. P. (2018). Metodologia da pesquisa e do trabalho científico. FUNEPE. http://funepe.edu.br/arquivos/publicacoes/metodologia-pesquisa-trabalho-cientifico.pdf. 